EDITORIAL | EDITORIAL

\title{
Funcionamento e desempenho do sistema de Revisão por Pares
}

\author{
Operation and performance of the Peer-Review system
}

Haroldo Vieira Moraes Jr., Eduardo Melani Rocha, Wallace Chamon

A revisão de manuscritos por especialistas no tema, e as sugestões deles incorporadas no trabalho ou usadas para rejeitá-los é chamada de revisão por pares ("peer-review system"). Esse recurso é usado de maneira regular desde o início do século XVIII, pela Medical Essays and Observations, de Edimburgo, Escócia e tem a sua efetividade reavaliada periodicamente ${ }^{(1)}$.

O sistema já foi definido como "uma negociação entre um autor e uma publicação acerca do âmbito de conhecimento que finalmente surgirão impressas"(2) ou como "uma avaliação, por peritos, da qualidade e pertinência da investigação de outros peritos do mesmo campo"(3). O sistema, também chamado de arbitragem científica, é considerado um dos pilares fundamentais da ciência, usado também para concessão de verbas para pesquisa e prêmios ou honrarias para pesquisadores.

Na década de 80, do século XX, ele passou a ser parte da maioria das agências de fomento e revistas biomédicas do mundo. Dois fatores principais contribuíram para a sua incorporação formal no processo de publicação científica: o crescimento exponencial do número de artigos submetidos, e sua crescente especialização, fenômenos observados também no Brasil e já comentados nos ABO, anteriormente ${ }^{(4-5)}$.

Curiosamente, esse crescimento também demonstrou algumas fraquezas do sistema ${ }^{(6)}$. Alguns estudos abordaram a fragilidade do processo de revisão por pares, mas poucos têm oferecido alternativas razoáveis ao modelo ${ }^{(7)}$. As críticas estão relacionadas a diversos pontos; como o tempo gasto no processo, o cerceamento da liberdade do leitor de fazer sua crítica completa e pessoal, além do inevitável viés dos revisores. Naturalmente, a revisão por pares também não é suficiente para evitar a fraude que, para ser combatida, sempre necessitará de ferramentas mais sofisticadas e, principalmente, da análise crítica dos leitores.

A maneira como o sistema é usado pode variar. Revistas prestigiadas como New England Journal of Medicine, The Lancet e outras aceitam entre 6 a 10\% dos manuscritos submetidos. Algumas rejeitam até $50 \%$ dos artigos submetidos de imediato, por meio de revisões técnicas, não levando ao conhecimento de revisores especialistas na área, outras chegam a cobrar taxas apenas para fazer a análise, mesmo que acabe numa rápida rejeição do material, sem direito a reembolso. Na maioria das revistas, os revisores têm conhecimento de quem são os autores, no entanto, o anonimato do revisor normalmente só é quebrado se este assim o desejar.

Como já observado pelo Prof. Harley Bicas, em editorial sobre rejeição de manuscritos, a decisão de rejeitar não é fácil de ser tomada, é passível de erro e a intenção dos ABO, ao tomar essa decisão é o melhor beneficio do leitor, procurando ser educativa para autores ${ }^{(8)}$.

Erros no processo de avaliação ocorrem dos dois lados, prova disso é que dentre as causas de rejeição ou pendência na literatura científica médica a inadequação da metodologia estatística é apontada como uma das mais freqüentes. Revistas importantes como Nature Medicine, chegaram a apresentar erros estatísticos em até $38 \%$ dos artigos publicados ${ }^{(9-10)}$. Neste contexto, programas de apoio à capacitação de autores e revisores científicos têm sido oferecidos pelos ABO nos Congressos Brasileiros, nos últimos anos.

Os $A B O$ agradecem anualmente os seus revisores e depositam neles a perspectiva de evolução e participação na sua qualidade ${ }^{(11)}$. Boas orientações para a execução dessa árdua e anônima tarefa existem na literatura ${ }^{(12)}$.

Algumas análises bibliométricas indicam que manuscritos enviados a dois ou mais revisores geralmente não obtêm concordância, sobre a qualidade do trabalho, maior do que seria ao acaso(13). Por outro lado, a priorização dada por revisores, publicando apenas manuscritos considerados "excelentes", elevaria consideravelmente o fator de impacto da revista, devolvendo a responsabilidade sobre a qualidade ao autor, que envia os seus melhores manuscritos, e aos revisores que avaliam cuidadosa e rapidamente o que recebem.

Na literatura internacional, o destino dos trabalhos rejeitados é a publicação em revistas de menor impacto, cerca de 18 meses após o envio inicial ${ }^{(14)}$. Nos ABO é observado que muitos autores com artigos pendentes não voltam a enviar o artigo com as revisões feitas ou argumentos para não atender ao pedido do revisor. Nesse casos, o trabalho fica interrompido unilateralmente, faltando dos autores uma satisfação ao empenho da revista em contribuir com a melhora do manuscrito. 0 desfecho desejado seria atender aos questionamentos, enviar uma réplica aos editores ou abdicar 
da intenção de publicação. Recentemente a política editorial dos ABO passou a excluir trabalhos pendentes com o autor por mais de três meses.

Em resumo, o trabalho de revisão por pares é sujeito a críticas, que devem ser levadas pelos autores, editores e revisores, para aperfeiçoamento do sistema. O sistema, por sua vez deve persistir, pois ainda é a melhor maneira de assegurar que a boa informação científica chegue aos leitores, até que uma alternativa melhor seja comprovada.

\section{REFERÊNCIAS}

1. Benos DJ, Bashari E, Chaves JM, Gaggar A, Kapoor N, LaFrance M, et al. The ups and downs of peer review. Adv Physiol Educ. 2007;31(2):145-52.

2. Goodman SN, Berlin J, Fletcher SW, Fletcher RH. Manuscript quality before and after peer review and editing at Annals of Internal Medicine. Ann Intern Med. 121(1):11-21, 1994. Comment in: Ann Intern Med. 1994;121()1):60-1.

3. Gitanjali B. Peer review - process, perspectives and the path ahead. J Postgrad Med. 2001;47(3):210-4.

4. Bicas HE, Dantas PE, Campos M, Muccioli C, Moral C. Sobre a editoração científica no Brasil e seu crescimento. Arq Bras Oftalmol [Internet]. 2008 [citado 2009 Jul 13];71(3):309. Disponível em: http://www.scielo.br/pdf/abo/v71n3/ a01v71n3.pdf

5. Moraes Jr HV. Reflexões sobre bioética. Arq Bras Oftalmol. 1997;60:661-2.

6. Gallagher R. Taking on peer review. The Scientist. 2006;20(2):13.
7. Turner L. Promoting F.A.I.T.H. in peer review: five core attributes of effective peer review. J Acad Ethics. 2003:1 (2):181-8.

8. Bicas HEA. Sobre rejeições de trabalhos encaminhados à publicação. Arq Bras Oftalmol. 2005;68(3):283-4.

9. Statistically significant. Nat Med. 2005;11(1):1.

10. McCook A. Is peer review broken? The Scientist. 2006;20(2): 26-34

11. Muccioli C, Campos M, Goldchmit M, Dantas PEC, Bechara SJ, Costa VP. Revisão de artigos científicos: privilégio para poucos; benefício para todos. Arq Bras Oftalmol [Internet]. 2006 [citado 2010 Jun 12];69(1):5. Disponível em: http://www.scielo.br/ pdf/abo/v69n1/27714.pdf

12. Turka LA. After further review. J Clin Invest. 2009;119(5):1057.

13. Rothwell PM, Martyn CN. Reproducibility of peer review in clinical neuroscience. Is agreement between reviewers any greater than would be expected by chance alone? Brain. 2000;123(Pt 9):1964-9.

14. Ray J, Berkwits M, DavidoffF. The fate of manuscripts rejected by a general medical journal. Am J Med. 2000;109(2):131-5. 